\section{Maraviroc: in vitro}

\section{assessment of drug-drug interaction potential}

\section{Ruth Hyland, Maurice Dickins, Claire Collins, Hannah Jones \&}

Barry Jones

Pharmacokinetics, Dynamics and Metabolism, Pfizer Global Research and Development, Sandwich, UK

\section{Correspondence}

Dr Ruth Hyland, Associate Research

Fellow, Pharmacokinetics Dynamics and Metabolism, Pfizer Global R\&D, Ramsgate Road, Sandwich, Kent CT13 9NJ, UK

Tel: + 441304641386

Fax: + 441304651987

E-mail: ruth.hyland@pfizer.com

\section{Keywords}

drug-drug interactions, in vitro metabolism, maraviroc, Simcyp ${ }^{\mathrm{TM}}$

\section{Received}

8 February 2008

Accepted

1 April 2008

\section{WHAT IS ALREADY KNOWN ABOUT} THE SUBJECT

Published OnlineEarly 22 July 2008

- Maraviroc is known to undergo oxidative metabolism in vivo and is a substrate for cytochrome P450 (CYP).

- Simcyp ${ }^{\mathrm{TM}}$ has recently become more widely used for the prediction of CYP-mediated drug-drug interactions (DDIs) using in vitro metabolism data.

\section{WHAT THIS STUDY ADDS}

- Maraviroc has been identified as a CYP3A4

substrate and the kinetic constants

characterized.

- The predicted DDIs associated with maraviroc as a CYP3A4 substrate using Simcyp ${ }^{\mathrm{TM}}$ have been compared against the clinical data.

- This study demonstrates the value of a reliable Simcyp ${ }^{T M}$ model for prediction of DDIs.

\section{AIMS}

To characterize the cytochrome P450 enzyme(s) responsible for the $\mathrm{N}$-dealkylation of maraviroc in vitro, and predict the extent of clinical drug-drug interactions (DDIs).

\section{METHODS}

Human liver and recombinant CYP microsomes were used to identify the CYP enzyme responsible for maraviroc N-dealkylation. Studies comprised enzyme kinetics and evaluation of the effects of specific CYP inhibitors. In vitro data were then used as inputs for simulation of DDIs with ketoconazole, ritonavir, saquinavir and atazanvir, using the Simcyp ${ }^{T M}$ population-based absorption, distribution, metabolism and elimination (ADME) simulator. Study designs for simulations mirrored those actually used in the clinic.

\section{RESULTS}

Maraviroc was metabolized to its $\mathrm{N}$-dealkylated product via a single CYP enzyme characterized by a $K_{m}$ of $21 \mu \mathrm{M}$ and $V_{\max }$ of $0.45 \mathrm{pmol} \mathrm{pmol}^{-1} \mathrm{~min}^{-1}$ in human liver microsomes and was inhibited by ketoconazole (CYP3A4 inhibitor). In a panel of recombinant CYP enzymes, CYP3A4 was identified as the major CYP responsible for maraviroc metabolism. Using recombinant CYP3A4, N-dealkylation was characterized by a $K_{m}$ of $13 \mu \mathrm{M}$ and a $V_{\max }$ of $3 \mathrm{pmol} \mathrm{pmol}^{-1} \mathrm{CYP} \mathrm{min}^{-1}$. Simulations therefore focused on the effect of CYP3A4 inhibitors on maraviroc pharmacokinetics. The simulated median AUC ratios were in good agreement with observed clinical changes (within twofold in all cases), although, in general, there was a trend for overprediction in the magnitude of the DDI.

\section{CONCLUSION}

Maraviroc is a substrate for CYP3A4, and exposure will therefore be modulated by CYP3A4 inhibitors. Simcyp ${ }^{\mathrm{TM}}$ has successfully simulated the extent of clinical interactions with CYP3A4 inhibitors, further validating this software as a good predictor of CYP-based DDIs. 


\section{Introduction}

Maraviroc (Figure 1) is a CC chemokine receptor 5 (CCR5) antagonist for the treatment of human immunodeficiency virus (HIV) infection. It is potent, orally bioavailable and has been shown to be effective and well tolerated in preclinical [1,2] and clinical studies [3]. It is generally accepted that combination pharmacotherapy for the treatment of HIV infection is the best approach for viral load reduction and clinical success. HIV-infected patients are frequently prescribed highly active antiretroviral therapy regimens, which typically consist of at least three different drugs, from at least two different classes, and currently include nucleoside reverse transcriptase inhibitors, nonnucleoside reverse transcriptase inhibitors, protease inhibitors and the entry inhibitor enfuvirtide [4]. Many of these agents are known to modulate the activity of important drug-metabolizing enzymes and transporters, such as CYP3A4 and P-glycoprotein (P-gp). Patients with HIV also have a high prevalence of co-morbid conditions that may require other medications [5]. Therefore, examination of drug interactions is a requisite step in the development of new HIV drugs, to determine their suitability for introduction into existing treatment regimens and define dose adjustments if necessary. In order to assess potential for drug-drug interactions (DDIs), knowledge of clearance mechanisms, enzymes responsible for major metabolic pathways and modulating capabilities of enzyme activities is essential. Through understanding of these mechanisms the likelihood for a new chemical entity to be the victim of a DDI can be assessed, in addition to predicting any potential the drug itself may have for interfering with clearance mechanisms of other agents. In vitro data can guide the clinical strategies for complex pharmacotherapy programmes.

The metabolite profile of maraviroc has been determined in male human volunteers $[2,6]$. Parent compound was the major component present in human urine, faeces and plasma, accounting for $33 \%$ of excreted radioactivity and $42 \%$ of plasma radioactivity. Several oxidized metabolites were identified in excreta, with oxidative pathways accounting for $53 \%$ of the excreted radioactivity. The most abundant metabolite detected in human plasma was a secondary amine product of N-dealkylation (UK-408,027) accounting for $22 \%$ of plasma radioactivity.

By characterizing the enzymes responsible for metabolism in human liver microsomes (HLM), an in vitro assessment of maraviroc as the victim of potential DDIs can be made. This study also describes investigations into the inhibitory potency of maraviroc against cytochrome P450, the major drug-metabolizing enzyme system. Through a combination of victim and perpetrator in vitro DDI data, we have been able to model successfully the DDIs observed for maraviroc with several CYP3A4 inhibitors using Simcyp ${ }^{\mathrm{TM}}$, a population-based simulator of DDI. Having access to such a model then allows for prediction of other DDIs without the need for a clinical study.

\section{Materials and methods}

\section{Drugs and chemicals}

Maraviroc (UK-427,857) and authentic metabolite (UK408,027) were synthesized at Pfizer Global Research and Development (Sandwich, UK). Furafylline, (S)-mephenytoin and (S)-4'-hydroxy mephenytoin were obtained from Salford Ultrafine Chemicals and Research Ltd (Manchester, UK). Specific CYP Supersomes ${ }^{\mathrm{TM}}$ and HLMs (prepared from a pool of 60 donors) were obtained from BD Biosciences (Bedford, MA, USA). All other reagents were of at least Analar grade quality, obtained from Sigma-Aldrich (Poole, UK).

\section{Assays for maraviroc metabolism}

Microsomal incubations (HLMs or recombinant CYPs) were performed under standard conditions. Each incubation (final volume $100 \mu \mathrm{l}$ ) comprised $50 \mathrm{mM}$ phosphate buffer ( $\mathrm{pH}$ 7.4) and $1 \mathrm{mM} \mathrm{MgCl}$. Reducing equivalents required for CYP metabolism were provided by nicotinamide adenine dinucleotide phosphate (NADPH) $(1 \mathrm{mM})$, which was regenerated in situ by an isocitric acid/isocitric acid dehydrogenase system. The incubation mixture was preincubated at $37^{\circ} \mathrm{C}$ in the presence of substrate prior to addition of NADPH. Samples were analysed for either loss of substrate or formation of the $\mathrm{N}$-dealkylated metabolite UK-408,027 using LC-MS/MS.

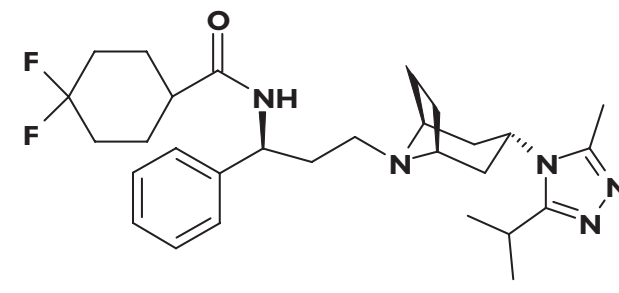

Maraviroc

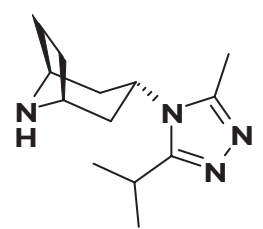

UK-408,027

\section{Figure 1}

Structures of maraviroc and UK-408,027 
Analytical conditions Samples were chromatographed on a chromolith monolithic $\mathrm{C} 18$ column $(5 \mathrm{~cm} \times 4.6 \mathrm{~mm})$ with a mobile phase of $A$, methanol:water (10:90) containing $2 \mathrm{mM}$ ammonium acetate and $0.27 \%$ formic acid, and B, methanol:water (90:10) containing $2 \mathrm{mM}$ ammonium acetate and $0.27 \%$ formic acid, at a flow rate of $3 \mathrm{ml} \mathrm{min}^{-1}$ using a stepped elution (0-0.5 $\mathrm{min} 100 \% \mathrm{~A}, 0.5-1.0 \mathrm{~min}$ $100 \%$ A to $100 \%$ B, $1.0-1.49$ min $100 \%$ B, 1.5 min $100 \%$ A, 1.5-2.2 min $100 \%$ A). Following chromatographic separation, the sample was split 50:1 using an Acutate ${ }^{\mathrm{TM}}$ splitter and delivered to a Sciex API3000 mass spectrometer. Analytes were measured in positive ion multiple reaction monitoring mode using the following transitions: maraviroc 514>389, UK-408,027 $235>110$, midazolam (IS) $326>291$, UK-412,069 (IS) $325>200$.

Maraviroc loss assay At the end of the incubation the reaction was terminated either by the addition of $100 \mu \mathrm{l}$ ice-cold acetonitrile or $2 \mathrm{ml}$ ethyl acetate and $1 \mathrm{ml} 0.2 \mathrm{M}$ borate buffer $\mathrm{pH}$ 9. Midazolam was used as internal standard in the assay. Acetonitrile precipitated samples were centrifuged and supernatant analysed directly by LC-MS/ MS. Ethyl acetate/borate extracted samples were rotary mixed, and the organic layer dried under vacuum. Samples were reconstituted in mobile phase $(200 \mu \mathrm{l})$ and analysed directly by LC-MS/MS. The coefficient of variation (CV) was $14 \%$ for $1 \mu \mathrm{M}$ maraviroc. The first-order rate constant $(k)$ was calculated by plotting the natural log of maraviroc peak area ratio (maraviroc area/midazolam area) against incubation time, and determining the gradient of the initial disappearance rate. The rate of maraviroc disappearance was then expressed as $\mu \mathrm{l} \mathrm{pmol}^{-1} \mathrm{CYP} \mathrm{min}^{-1}$.

Metabolite formation assay At the end of the incubation the reaction was terminated by the addition of $500 \mu \mathrm{l}$ icecold $0.2 \%$ acetic acid containing UK-412,069, an internal standard structurally related to UK-408,027. Samples were extracted using a 50-mg Certify 96-well block. Following elution in a acetonitrile:water (50:50) mix containing 5\% ammonia, samples were centrifuged and the supernatant analysed directly by LC-MS/MS. The amount of UK-408,027 formed in the incubations was determined by interpolation from standard curves constructed in microsomal incubates from 1 to $500 \mathrm{ng}$ UK-408,027 (CV was 5.7, 5.1 and $4.2 \%$ for concentrations of 5,50 and $150 \mathrm{ng}$, with mean inaccuracies of $3.6,-5.8$ and $-2.4 \%$, respectively). The rate of UK-408,027 formation was expressed as pmol UK-408,027 formed $\mathrm{pmol}^{-1} \mathrm{CYP} \mathrm{min}^{-1}$.

\section{Maraviroc kinetics in human liver microsomes}

The rate of formation of UK-408,027 was determined in HLMs. Initial studies were conducted to optimize the incubation time and protein concentration before the kinetic study, which was conducted over a maraviroc concentration range of $1-1000 \mu \mathrm{M}$. Rates of UK-408,027 formation were analysed to obtain values for $K_{m}$ and $V_{\text {max }}$.

\section{Chemical inhibition studies}

The effect of various specific inhibitors of CYP enzymes on maraviroc metabolism was investigated in microsomes prepared from a pool of 60 human livers. The inhibitors (furafylline:CYP1A2, sulphaphenazole:CYP2C9, benzylnirvanol:CYP2C19, quinidine:CYP2D6, ketoconazole: CYP3A4) were chosen on the basis of selective inhibition of a particular CYP enzyme, and the concentrations used had been previously established to cause significant inhibition of that CYP [7]. For the mechanism-based inhibitor, furafylline, a 15-min preincubation period was used. For substrate loss experiments, inhibitors were co-incubated with maraviroc $(1 \mu \mathrm{M})$ at $0.5 \mu \mathrm{M}$ CYP for up to $60 \mathrm{~min}$. For UK-408,027 formation studies, inhibitors were coincubated with maraviroc $(50 \mu \mathrm{M})$ at $0.1 \mathrm{mg} \mathrm{m}^{-1}$ microsomal protein for $15 \mathrm{~min}$. The effect of inhibitors on both maraviroc intrinsic clearance and UK-408,027 formation was measured.

\section{Metabolism of maraviroc by expressed recombinant CYPS}

Incubations were performed at 100 pmol recombinant CYP (rCYP) for up to 60 min with maraviroc at $1 \mu \mathrm{M}$ (parent loss) and $50 \mu \mathrm{M}$ (UK-408,027 formation) in Supersomes ${ }^{\mathrm{TM}}$ expressing individual CYP enzymes. Rates of maraviroc metabolism were expressed as intrinsic clearance or UK-408,027 formation, respectively. Kinetic characterization of UK-408,027 formation was performed in rCYP3A4 Supersomes ${ }^{\mathrm{TM}}$ after first establishing assay linearity with respect to time and CYP concentration. Incubations were performed across a maraviroc concentration range of $1-1000 \mu \mathrm{M}$.

\section{Inhibition of CYP enzymes by maraviroc}

The effect of maraviroc (up to $30 \mu \mathrm{M}$ ) on the metabolism of probe substrates for specific CYP enzymes was investigated in a pool of HLMs. Substrates used were $20 \mu \mathrm{M}$ phenacetin (CYP1A2), $100 \mu \mathrm{M}$ bupropion (CYP2B6), $9 \mu \mathrm{M}$ rosiglitazone (CYP2C8), $18 \mu \mathrm{M}$ diclofenac (CYP2C9), $37 \mu \mathrm{M}$ (S)-mephenytoin (CYP2C19), $4 \mu \mathrm{M}$ dextromethorphan (CYP2D6), $120 \mu \mathrm{M}$ testosterone (CYP3A4), $3 \mu \mathrm{M}$ midazolam (CYP3A4) and $20 \mu \mathrm{M}$ felodipine (CYP3A4). Specific assays used were those previously described in the literature $[8,9]$. Samples were preincubated in the presence and absence of maraviroc for $5 \mathrm{~min}$ at $37^{\circ} \mathrm{C}$ prior to the addition of NADPH.

\section{Simcyp $p^{T M}$ simulations}

A clinical DDI programme was conducted for maraviroc, and the clinical data were used to validate predictions. The predicted effect of co-administration of the CYP3A4 inhibitors on maraviroc exposure was determined using Simcyp ${ }^{\mathrm{TM}}$. Simulations were carried out using the Simcyp ${ }^{\mathrm{TM}}$ population-based absorption, distribution, metabolism and elimination (ADME) simulator (version 7.01) using 
time-based and steady-state simulations. The time-based model accounts for time- and concentration-dependent enzyme inhibition using unbound plasma concentrations. The simulations in this mode were generated using the actual study design used in the clinical DDI studies, where both maraviroc and the inhibitor were dosed daily at the following doses. The effects of ketoconazole ( $400 \mathrm{mg} \mathrm{qd}$ ), ritonavir (100 mg bid) or saquinavir (1200 $\mathrm{mg}$ tid) on the pharmacokinetics of maraviroc (100 $\mathrm{mg}$ bid) and the effect of atazanavir ( $400 \mathrm{mg} \mathrm{qd}$ ) on maraviroc ( $300 \mathrm{mg}$ bid), as dosed in the clinical studies [10], were simulated. Plasma concentration-time profiles were generated for both the substrate and the inhibitor in this mode. The simulations were repeated using a trial design where both maraviroc and the inhibitor were at steady-state concentration.

Input parameters for maraviroc and atazanavir $[11,12]$ are shown in Table 1. For maraviroc, $\mathrm{CL}_{\text {int }}$ input was generated from the rCYP3A4 metabolism data with appropriate correction [13]. For inhibitors other than atazanavir, inputs were supplied by the program. In addition, inactivation parameters for the CYP3A mechanism-based inhibitor

\section{Table 1}

\begin{tabular}{|c|c|}
\hline \multicolumn{2}{|c|}{ Simcyp ${ }^{\text {тм }}$ inputs for maraviroc } \\
\hline Parameter & Value \\
\hline Molecular weight & 513.7 \\
\hline $\log P$ & 2.4 \\
\hline $\mathrm{p} K_{a}$ (basic) & 7.3 \\
\hline Blood/plasma ratio & 0.59 \\
\hline$f_{u}$ (plasma) & 0.25 \\
\hline$F_{a}$ & $0.58(100 \mathrm{mg}) ; 0.83(300 \mathrm{mg})$ \\
\hline$K_{a}\left(\mathrm{~h}^{-1}\right)$ & 0.5 \\
\hline$V_{s s}\left(\mathrm{~kg}^{-1}\right)$ & 2.5 \\
\hline $\mathrm{CL}_{\text {int }}\left(\right.$ (rhCYP3A4) $\left(\mu \mathrm{l} \mathrm{min}{ }^{-1} \mathrm{pmol}^{-1}\right)$ & 1.7 (0.34 after ISEF adjustment) \\
\hline$f_{u(\text { mic })}$ & 0.86 \\
\hline $\mathrm{CL}_{R}\left(\mathrm{I} \mathrm{h}^{-1}\right)$ & 12 \\
\hline \multicolumn{2}{|c|}{ Simcyртм inputs for atazanavir } \\
\hline Parameter & Value \\
\hline Molecular weight & 704.9 \\
\hline $\log P$ & 2.12 \\
\hline $\mathrm{p} K_{a}$ & Neutral \\
\hline Blood/plasma ratio & 0.75 \\
\hline$f_{u}$ (plasma) & 0.14 \\
\hline$F_{a}$ & 1 \\
\hline$K_{a}\left(\mathrm{~h}^{-1}\right)$ & 1.5 \\
\hline$V_{\mathrm{ss}}\left(\mathrm{kgg}^{-1}\right)$ & 1.2 \\
\hline $\mathrm{CL} / F\left(\mathrm{~h} \mathrm{~h}^{-1}\right)$ & 20 \\
\hline $\mathrm{CL}_{R}\left(\mathrm{I} \mathrm{\textrm {h } ^ { - 1 } )}\right.$ & 0.5 \\
\hline \multicolumn{2}{|l|}{ CYP3A4 } \\
\hline$K_{i}$ (reversible) $(\mu \mathrm{M})$ & 2.3 \\
\hline$K_{l}(\mu \mathrm{M})$ & 1 \\
\hline$k_{\text {inact }}\left(\mathrm{h}^{-1}\right)$ & 3.6 \\
\hline$f_{u(\text { mic })}$ & 1 \\
\hline
\end{tabular}

ISEF, intersystem extrapolation factor. saquinavir were $K_{l}=0.65 \mu \mathrm{M}$ and $k_{\text {inact }}=15.6 \mathrm{~h}^{-1}$ [14]. The values of $k_{\text {deg }}$ used for the degradation constants of hepatic and intestinal CYP3A were $0.05 \mathrm{~h}^{-1}$ and $0.03 \mathrm{~h}^{-1}$, respectively $[15,16]$. The input parameters for the physicochemical properties, blood:plasma ratio and fraction unbound in plasma $\left(f_{u(\text { plasma })}\right)$ for the maraviroc Simcyp ${ }^{\mathrm{TM}}$ model used data generated at Pfizer [2].

A physiologically based pharmacokinetic model was used for maraviroc in Simcyp ${ }^{\mathrm{TM}}$. Tissue to plasma partition coefficient $\left(K_{p}\right)$ values were estimated using mechanistic tissue composition equations developed by Poulin and co-workers [17] with LogP, LogD and $f_{u(\text { plasma) }}$ as input.

Data for absorption and renal clearance of unchanged drug at the dose levels used in the drug interaction studies were obtained from clinical studies and following administration of ${ }^{14} \mathrm{C}$-maraviroc $[2,6]$.

\section{Microsomal binding of maraviroc}

To determine microsomal binding, a HLM incubation was prepared as described above, omitting the addition of $\mathrm{NADP}^{+}$, and left at room temperature overnight. The following morning maraviroc was spiked into the mixture at a final concentration of $1 \mu \mathrm{M}$. Aliquots $(3 \times 400 \mu \mathrm{l})$ of the microsomal mixture containing maraviroc were added to an ultrafiltration plate (Millipore, Billerica, MA, USA; catalogue no. MAPPB1010). Nine aliquots $(400 \mu \mathrm{l})$ of control microsomal incubation (without maraviroc) were also added to the ultrafiltration plate for construction of a calibration line and for matrix matching of samples prior to analysis. The ultrafiltration plate was centrifuged at $2000 \mathrm{~g}$ for $50 \mathrm{~min}$ at $37^{\circ} \mathrm{C}$. Filtrate $(50 \mu \mathrm{l})$ was sampled from the bottom of the ultrafiltration plate into a 96-well block and a calibration line (10-1000 ng) spiked into control filtrate. An aliquot $(50 \mu \mathrm{l})$ of the microsome mixture retained in the top of the plate was placed into a well of a 96-well block. All samples were matrix matched in the following way. To every filtrate sample, control microsome mixture retained in the top of the plate $(50 \mu \mathrm{l})$ was added. To each sample of microsome mixture retained in the top of the plate, control filtrate $(50 \mu \mathrm{l})$ was added. All samples were precipitated with acetonitrile $(80 \mu \mathrm{l})$ containing internal standard. Samples were centrifuged [3000 rpm $(1730 \mathrm{~g})$ for $30 \mathrm{~min}$ ] and analysed by LC/MS-MS. The concentration of maraviroc in the samples was interpolated from a standard curve of peak area ratio vs. spiked concentration. The fraction unbound in microsomes was calculated from

$$
\text { Fraction unbound }=\operatorname{conc}^{n} \text { filtrate } / \operatorname{conc}^{n} \text { total }
$$

The recovery in the experiment was calculated from

$$
\begin{aligned}
\text { Mass balance }= & (\text { mass filtrate }+ \text { mass retentate }) / \\
& \text { mass initial } \times 100
\end{aligned}
$$

where mass $(\mathrm{ng})=($ concentration $/ 1000) \times$ volume $($ typical volumes are $50 \mu \mathrm{l}$ filtrate and $350 \mu \mathrm{l}$ retentate). Recoveries of $80-120 \%$ were considered acceptable. 


\section{Analysis of results}

All results are presented as mean \pm SD. Determination of apparent $K_{m}$ and $V_{\max }$ values were obtained by Grafit (version 4). Statistical analysis was carried out using Microsoft Excel (version 5) using either a one-sided $t$-test or two-sided $t$-test for independent variables.

\section{Results}

\section{Kinetics of maraviroc $N$-dealkylation in human} liver microsomes

The rate of formation of UK-408,027 in HLMs was found to be linear with time up to $20 \mathrm{~min}$ and protein up to $0.5 \mathrm{mg} \mathrm{ml}^{-1}$. Enzyme kinetics were determined at a protein concentration of $0.1 \mathrm{mg} \mathrm{ml}^{-1}$ over $15 \mathrm{~min}$. At this protein concentration, based upon available microsomal binding data, maraviroc is calculated to be $98 \%$ free, hence the apparent $K_{m}$ will be close to the real $K_{m}$. The apparent kinetic constants were estimated using maraviroc concentrations up to $1000 \mu \mathrm{M}$. Analysis of samples incubated in the absence of NADPH and also with maraviroc spiked into unincubated samples revealed a concentrationdependent contaminant, which may have been a small amount of UK-408,027 present as an impurity. The apparent Michaelis-Menten kinetic parameters were therefore estimated incorporating a term for the impurity by fitting the data to the following equation:

$$
\mathrm{v}=\frac{\mathrm{Vmax} \cdot[\mathrm{S}]}{\mathrm{Km}+[\mathrm{S}]}+\mathrm{C}[\mathrm{S}]
$$

where $v$ is the velocity of formation of UK- $408,027, S$ is the concentration of maraviroc in the incubation mixture, $\mathrm{Ca}$ constant representing the proportion of impurity, $K_{m}$ the Michaelis-Menten constant and $V_{\max }$ maximum velocity. The curve fit is illustrated in Figure 2, and the calculated kinetic parameters were a $K_{m}$ of $21 \mu \mathrm{M}$ and $V_{\max }$ of $0.45 \mathrm{pmol} \mathrm{pmol}^{-1} \mathrm{CYP} \mathrm{min}^{-1}$. In one experiment the amount of impurity across the substrate concentration range was also determined, and rates of UK-408,027 formation corrected for this. Fitting these data to a standard Michaelis-Menten equation gave a similar $K_{m}$ and $V_{\max }$ to fitting uncorrected data to the above equation (data not shown).

\section{Inhibition of maraviroc metabolism in human liver microsomes}

The effects of specific CYP inhibitors on maraviroc metabolism at $1 \mu \mathrm{M}$ (substrate loss) and $50 \mu \mathrm{M}$ (metabolite appearance) were investigated. The results of this investigation are summarized in Table 2 .

Maraviroc metabolism is clearly inhibited by ketoconazole, with $<80 \%$ of control activity remaining. There was no significant effect on metabolic activity in the presence of

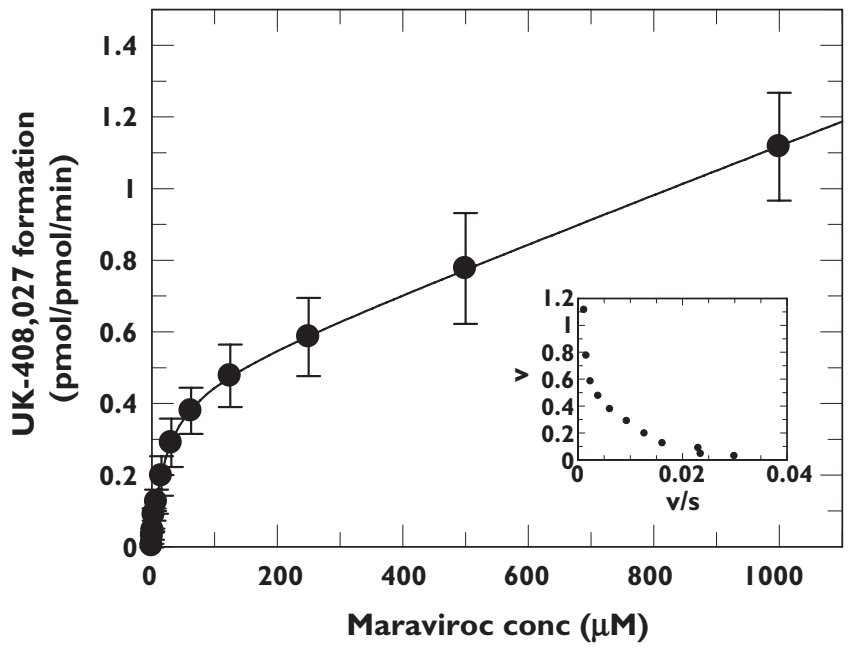

Figure 2

Michaelis-Menten and Eadie-Hofstee (inset) plots for the conversion of maraviroc to UK-408,027 in human liver microsomes. The values are mean \pm SD from seven determinations.

any of the other CYP inhibitors. These data suggest that CYP3A4 is responsible for the metabolism of maraviroc.

\section{Metabolism of maraviroc in expressed recombinant CYPS}

Maraviroc metabolism was investigated in Supersomes ${ }^{\mathrm{TM}}$ expressing recombinant CYP1A2, CYP2B6, CYP2C8, CYP2C9, CYP2C19, CYP2D6, CYP3A4 and CYP3A5 by substrate depletion and metabolite appearance at $1 \mu \mathrm{M}$ and $50 \mu \mathrm{M}$ maraviroc, respectively (Figure 3). Under the assay condition used for substrate depletion, the lower limit for accurately measuring a disappearance rate was set at $0.06 \mu \mathrm{l} \mathrm{pmol}^{-1} \mathrm{~min}^{-1}$, anything more stable than this being classified at $<0.06 \mu \mathrm{pmol}^{-1} \mathrm{~min}^{-1}$. A one-sided $t$-test identified those incubations where maraviroc depletion rate was significantly different from $0.06 \mu \mathrm{pmol}^{-1} \mathrm{~min}^{-1}$. Only in incubations with rCYP3A4 was the rate of metabolism significantly greater than the assay cut-off. For recombinant CYP incubations measuring UK-408,027, data were compared with those in control Supersomes ${ }^{\mathrm{TM}}$, to identify UK-408,027 formation above the small amount of contaminant present in the substrate. CYP3A4 was again the major contributor to maraviroc formation, whereas for CYP2B6, a small, but statistically significant amount of UK-408,027 was also produced.

\section{Kinetics of maraviroc N-dealkylation by rCYP3A4}

The rate of formation of UK-408,027 in rCYP3A4 Supersomes $^{\mathrm{TM}}$ was linear with time up to $20 \mathrm{~min}$ and CYP content up to $50 \mathrm{pmol} \mathrm{ml}^{-1}$. Kinetic studies with rCYP3A4 were performed at $10 \mathrm{pmol} \mathrm{ml}^{-1}$ for $15 \mathrm{~min}$ over a substrate concentration range of 1-1000 $\mu \mathrm{M}$. At this CYP con- 
Effect of specific CYP inhibitors on maraviroc metabolism in human liver microsomes

\begin{tabular}{|c|c|c|}
\hline Inhibitor (CYP) & $\begin{array}{l}\text { Inhibition (\% of contrc } \\
\text { UK- } 408,027 \text { formation }\end{array}$ & Maraviroc depletion \\
\hline $30 \mu \mathrm{M}$ furafylline (CYP1A2) & $85.0 \pm 15.8$ & ND \\
\hline $10 \mu \mathrm{M}$ sulphaphenazole (CYP2C9) & $108.1 \pm 27.7$ & $99.1 \pm 5.3$ \\
\hline $10 \mu \mathrm{M}$ benzylnirvanol (CYP2C19) & $85.4 \pm 47$ & ND \\
\hline $1 \mu \mathrm{M}$ quinidine (CYP2D6) & $102.2 \pm 20.2$ & $100.3 \pm 16.0$ \\
\hline $1 \mu \mathrm{M}$ ketoconazole (CYP3A4) & $16.1 \pm 5.7^{*}$ & $17.3 \pm 3.4^{*}$ \\
\hline
\end{tabular}

* $P<0.00001$ compared with control activity. ND, not determined. Maraviroc concentrations were $50 \mu \mathrm{M}$ and $1 \mu \mathrm{M}$ for UK-408,027 formation and substrate depletion, respectively. Values are mean $\pm S D$ of quadruplicate determinations. Uninhibited control activities: UK-408,027 formation, $75.9 \mathrm{pmol} \mathrm{mg}^{-1} \mathrm{~min}^{-1}$; maraviroc depletion, $0.106 \mu$ pmol ${ }^{-1} \mathrm{~min}^{-1}$.

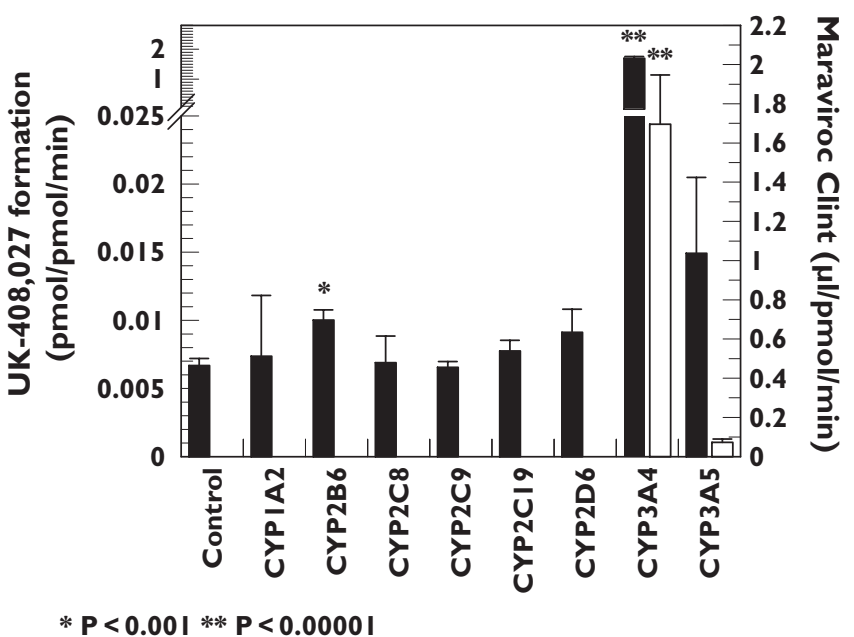

\section{Figure 3}

Rate of maraviroc N-dealkylation (left axis, solid bars) and maraviroc intrinsic clearance (right axis, open bars) in a panel of rCYP Supersomes ${ }^{\mathrm{TM}}$. Maraviroc concentrations were $50 \mu \mathrm{M}$ and $1 \mu \mathrm{M}$ for metabolite formation and substrate depletion, respectively. Each value is mean $\pm \mathrm{SD}, n=4$ (UK-408,027 formation, ( $\square$ ); Maraviroc Clint, $(\square)$ )

centration, based upon available microsomal binding data, maraviroc is calculated to be $98 \%$ free, hence the apparent $K_{m}$ will be close to the real $K_{m}$. Data analysis indicated that the rCYP3A4-mediated $\mathrm{N}$-dealkylation of maraviroc was characterized by a $K_{m}$ of $13 \mu \mathrm{M}$ and a $V_{\max }$ of $3 \mathrm{pmol} \mathrm{pmol}^{-1}$ CYP $\min ^{-1}$ (Figure 4). This $K_{m}$ value is consistent with $K_{m}$ in HLMs.

\section{In vitro inhibition of CYP enzymes by maraviroc}

Inhibition of CYP activity was investigated at concentrations up to $30 \mu \mathrm{M}$ maraviroc. Over this concentration range maraviroc was a weak inhibitor, with $\mathrm{IC}_{50}$ values of $>30 \mu \mathrm{M}$ against all CYP probe substrates investigated. The greatest effect was observed against midazolam as a CYP3A4 probe, where $65 \%$ of midazolam 1-hydroxylase activity remained at $30 \mu \mathrm{M}$ maraviroc (data not shown). The addi-

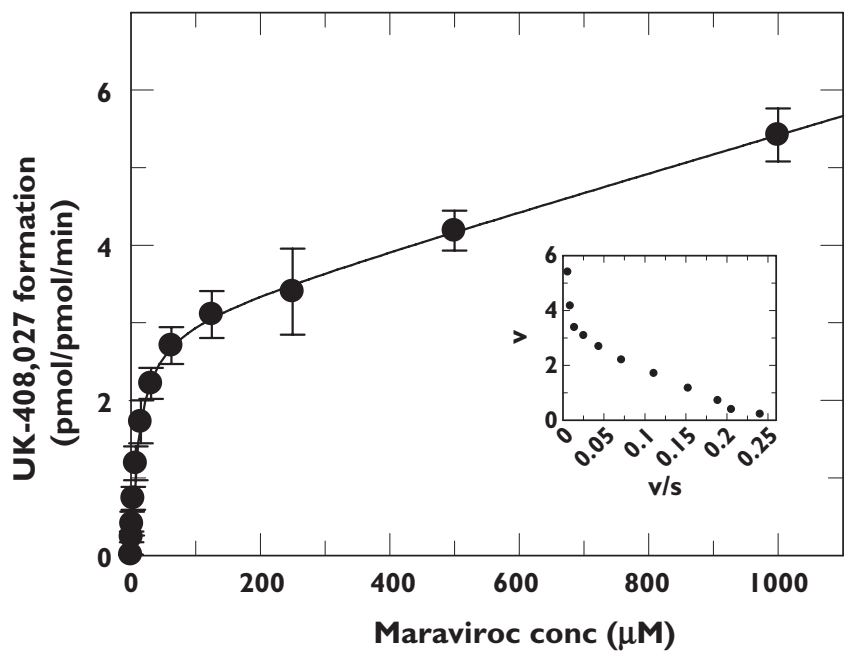

Figure 4

Michaelis-Menten and Eadie-Hofstee (inset) plots for the conversion of maraviroc to UK-408,027 in rCYP3A4 Supersomes ${ }^{\mathrm{TM}}$. The values are mean \pm SD from four determinations

tional CYP3A4 probes testosterone and felodipine showed no more than $10 \%$ inhibition at $30 \mu \mathrm{M}$ maraviroc (data not shown).

\section{CLint estimates from HLM and rCYP}

Substrate disappearance $\mathrm{CL}_{\text {int }}$ values were used for the $\mathrm{CL}_{\text {int }}$ input for maraviroc in the Simcyp ${ }^{\mathrm{TM}}$ model. These experiments were carried out at a substrate concentration of $1 \mu \mathrm{M}$, which was substantially below the $K_{m}$ for the major CYP3A4-mediated metabolite (21 and $13 \mu \mathrm{M}$ in HLM and rCYP3A4, respectively).

The $\mathrm{CL}_{\text {int }}$ for maraviroc in HLM was $0.106 \mu \mathrm{Imin}^{-1} \mathrm{pmol}^{-1}$ of total CYP (Table 1), corresponding to a $\mathrm{CL}_{\text {int }}$ of $35.0 \mu \mathrm{min}^{-1} \mathrm{mg}^{-1}$ microsomal protein (HLM total CYP concentration $=330 \mathrm{pmol} \mathrm{mg}^{-1}$ ). The corresponding $\mathrm{CL}_{\text {int }}$ in $\mathrm{rCYP3A} 4$ was $1.7 \mu \mathrm{min}^{-1} \mathrm{pmol}^{-1} 3 \mathrm{~A} 4$ (Figure 3), which was corrected to $0.34 \mu \mathrm{min}^{-1} \mathrm{pmol}^{-1}$ using an intersystem extrapolation factor [13] of 0.2 for CYP3A4. A CL int of $40.8 \mu \mathrm{l} \mathrm{min}^{-1} \mathrm{mg}^{-1}$ was calculated (using 


\section{Table 3}

Effectsofinhibitorsonmaraviroc $C_{\max }$ and AUC - comparison of clinical results and Simcyp ${ }^{\mathrm{TM}}$ simulations

\begin{tabular}{|c|c|c|c|c|c|c|c|c|}
\hline \multirow[b]{2}{*}{$\begin{array}{l}\text { Maraviroc } \\
\text { (mg) }\end{array}$} & \multirow[b]{2}{*}{ Inhibitor } & \multirow[b]{2}{*}{$\begin{array}{l}\text { Inhibitor } \\
\text { dose }(\mathbf{m g})\end{array}$} & \multicolumn{2}{|c|}{$\begin{array}{l}\text { Maraviroc } C_{\max } \text { increase } \\
\text { (fold change) }\end{array}$} & \multicolumn{4}{|c|}{ Maraviroc AUC increase (fold change) } \\
\hline & & & $\begin{array}{l}\text { Clinical } \\
\text { Mean }\end{array}$ & $\begin{array}{l}\text { SimCYP } \\
\text { Mean }\end{array}$ & $\begin{array}{l}\text { Clinical } \\
\text { Mean }\end{array}$ & $90 \% \mathrm{Cl}$ & $\begin{array}{l}\text { SimCYP } \\
\text { Median }\end{array}$ & $90 \% \mathrm{Cl}$ \\
\hline 100 bid & Ketoconazole & $400 \mathrm{qd}$ & 3.4 & 3.4 & 5.0 & $(4.0,6.3)$ & $\begin{array}{l}4.6 \mathrm{~TB} \\
5.2 \mathrm{SS}\end{array}$ & $\begin{array}{l}(2.7,9.1) \\
(2.8,10.6)\end{array}$ \\
\hline 100 bid & Ritonavir & $100 \mathrm{bid}$ & 1.3 & 2.3 & 2.6 & $(1.9,3.6)$ & $\begin{array}{l}2.6 \mathrm{~TB} \\
2.6 \mathrm{SS}\end{array}$ & $\begin{array}{l}(1.9,4.7) \\
(1.8,4.6)\end{array}$ \\
\hline 300 bid & Atazanavir & 400 qd & 2.1 & 3.6 & 3.6 & $(3.3,3.9)$ & $\begin{array}{l}5.0 \mathrm{~TB} \\
4.9 \mathrm{SS}\end{array}$ & $\begin{array}{l}(2.4,7.8) \\
(2.6,9.6)\end{array}$ \\
\hline 100 bid & Saquinavir & 1200 tid & 3.3 & 4.1 & 4.3 & $(3.5,5.2)$ & $\begin{array}{l}5.8 \mathrm{~TB} \\
3.5 \mathrm{SS}\end{array}$ & $\begin{array}{l}(2.8,12.0) \\
(2.0,8.7)\end{array}$ \\
\hline
\end{tabular}

SS, steady state; TB, time based.

the measured CYP3A4 content in the HLM batch of $120 \mathrm{pmol} \mathrm{mg}^{-1}$ ).

The free fraction in microsomes $\left(f_{u(\text { mic }}\right)$ was measured at the protein concentration used in the in vitro assay (1.5 mg ml${ }^{-1}$ ) and was 0.72 for HLM. For rCYP3A4, the incubations were carried out at an enzyme concentration of $100 \mathrm{pmol} \mathrm{ml}^{-1}$ (corresponding to a protein concentration of $0.63 \mathrm{mg} \mathrm{ml}^{-1}$ ), and a $f_{u(\text { mic) }}$ of 0.86 was calculated [18]. After adjustment for $f_{u(\text { mic })}, \mathrm{CL}_{\text {int }} \mathrm{HLM}=48.6 \mu \mathrm{m} \mathrm{min}^{-1} \mathrm{mg}^{-1}$ and $\mathrm{CL}_{\text {int }}$ rCYP3A4 $=47.4 \mu \mathrm{min}^{-1} \mathrm{mg}^{-1}$ protein.

\section{Clinical oral clearance values for maraviroc} and comparison with Simcyp ${ }^{T M}$ simulations

The clinical oral clearance $(\mathrm{CL} / F)$ values for maraviroc $100 \mathrm{mg}$ bid in the placebo leg of DDI studies with ketoconazole, ritonavir and saquinavir were 161.6, 167.5 and $205.3 \mathrm{I} \mathrm{h}^{-1}$, respectively [10], whereas the corresponding prediction from Simcyp ${ }^{\mathrm{TM}}$ for maraviroc at this dose was $144.0 \mathrm{I} \mathrm{h}^{-1}$ [90\% confidence interval (CI) 44.2, 237.1). Likewise, the $\mathrm{CL} / F$ value for maraviroc $300 \mathrm{mg}$ bid in the placebo leg of the atazanavir study was $107.5 \mathrm{I} \mathrm{h}^{-1}$ [10], whereas the corresponding prediction from Simcy ${ }^{\mathrm{TM}}$ was $102.3 \mathrm{I} \mathrm{h}^{-1}(90 \% \mathrm{Cl} 31.5,178.6)$.

\section{Clinical DDI values for maraviroc and comparison with Simcyp ${ }^{T M}$ simulations}

The results of simulations for the DDIs, expressed as $C_{\max }$ and AUC ratios, are shown in Table 3. The simulated median values were in good agreement with mean clinical changes for increases in AUC for both steady-state and time-based (TB) simulations for the inhibitors (within twofold in all cases), although, in general, there was a trend to overprediction in the magnitude of the DDI by Simcyp ${ }^{\mathrm{TM}}$. In the case of the TB simulations, the maraviroc plasma concentration-time profiles were also simulated, and the mean $C_{\max }$ increases in the presence of the inhibitors were in good agreement with the clinical data.

\section{Discussion}

The present study has investigated the major enzymes responsible for the metabolism of maraviroc and the potential for maraviroc to inhibit the major CYP enzymes. In addition, the in vitro data from HLMs and recombinant human CYP systems have been used to simulate the magnitude of clinically relevant DDIs for maraviroc.

Maraviroc is N-dealkylated by HLMs to UK-408,027, which is the most abundant circulating metabolite in man [2]. To identify the CYP enzymes responsible for maraviroc metabolism in human liver, experiments were first performed using HLM to understand the kinetics of UK-408,027 formation. The kinetic parameters were $K_{m}$ of $21 \mu \mathrm{M}$ and $V_{\max }$ of $0.45 \mathrm{pmol} \mathrm{pmol}^{-1} \mathrm{~min}^{-1}$. In HLMs the intrinsic clearance based upon UK-408,027 formation is approximately $20 \%$ of maraviroc intrinsic clearance calculated from substrate depletion experiments, a value consistent with data from the human radiolabel study, which shows multiple routes of metabolism [2].

Further studies to identify the individual CYP were performed at $1 \mu \mathrm{M}$ maraviroc (substrate depletion) and $50 \mu \mathrm{M}$ maraviroc (UK-408,027 formation), and employed a combination of chemical inhibition and metabolism by recombinant CYP enzymes. Of the specific inhibitors examined, ketoconazole (a potent/specific CYP3A4 inhibitor) strongly inhibited metabolism of maraviroc ( $>80 \%$ inhibition) and was the only statistically significant inhibitor. In experiments with recombinant human CYP enzymes, maraviroc was clearly metabolized by rCYP3A4 in terms of both substrate depletion and UK-408,027 formation. Compared with control incubations, formation of UK-408,027 was also statistically significant in rCYP2B6; however, the formation rate $\left(0.1 \mathrm{pmol} \mathrm{pmol}^{-1} \mathrm{~min}^{-1}\right)$ was 17 -fold lower than that observed for rCYP3A4 $\left(1.7 \mathrm{pmol} \mathrm{pmol}{ }^{-1} \mathrm{~min}^{-1}\right)$. Given the lower metabolic rate and the approximately 10 -fold lower expression levels of CYP2B6 protein compared with CYP3A4 protein in human liver, it is anticipated that the 
contribution by CYP2B6 will be minimal [19]. In substrate loss experiments there was also a small amount of substrate depletion observed for CYP3A5, although not statistically significant $(P>0.05)$ compared with the experimental cut-off of $0.06 \mu \mathrm{l} \mathrm{pmol}^{-1} \mathrm{~min}^{-1}$. With the overlapping substrate specificities for CYP3A4 and CYP3A5, is not surprising that both enzymes have the ability to metabolize maraviroc [20]. However, intrinsic clearance for $3 \mathrm{~A} 5$ is 25 -fold lower than that of CYP3A4, indicating that it will have only a minor role in maraviroc clearance. Further kinetic experiments characterized the rCYP3A4-mediated formation of UK-408,027 by a $K_{m}$ of $13 \mu \mathrm{M}$ and a $V_{\max }$ of

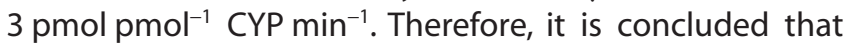
CYP3A4 is the only clinically relevant enzyme responsible for the metabolism of maraviroc in humans.

To investigate the potential inhibitory effects of maraviroc, $I_{50}$ values for the major human liver CYP enzymes were determined. The $I_{50}$ values of maraviroc for the metabolism of CYP1A2, CYP2B6, CYP2C8, CYP2C9, CYP2C19, CYP2D6 and CYP3A4 substrates were $>30 \mu \mathrm{M}$, which is much higher than the clinical plasma concentration (300 mg bid, $C_{\max } 1.7 \mu \mathrm{M}$ [21]). These results indicate that maraviroc is not likely to inhibit significantly drug metabolism mediated by CYP enzymes. This conclusion is consistent with the clinical DDI study, which was designed to investigate the effect of maraviroc on a CYP3A4 substrate (midazolam), since this was the enzyme on which maraviroc had the greatest inhibitory effect (35\% inhibition at $30 \mu \mathrm{M}$ maraviroc). In that study, maraviroc at a dose of $300 \mathrm{mg}$ maraviroc bid had only a minor influence on midazolam pharmacokinetics (geometric mean AUC ratio of midazolam + maraviroc compared with midazolam alone of $118 \%$ ) [22].

The in vitro data indicate that in terms of CYP-based, clinically significant DDIs, maraviroc is unlikely to be the perpetrator of such an interaction; however, it may be a victim. From in vitro data the metabolic clearance of maraviroc is almost exclusively mediated via CYP3A4. Full kinetic characterization of the most abundant circulating metabolite has been performed; however, other oxidative metabolites are known to be formed in microsomal incubations. These metabolites are also observed in vivo [2]. From substrate depletion experiments using specific CYP inhibitors and in rCYP incubations, we have demonstrated that CYP3A4 is the major enzyme involved in the additional oxidative pathways. Also, the intrinsic clearance estimates based on HLM and rCYP3A4 are very similar, providing further evidence for CYP3A4 being the major enzyme involved in oxidative metabolism of maraviroc. Pharmacokinetics of maraviroc are therefore likely to be influenced by co-administration of CYP3A4 inhibitors. Simulations were therefore performed to look at the effect of co-administration of several CYP3A4 inhibitors (ketoconazole, ritonavir, atazanavir and saquinavir), and the output compared with the results of the clinical DDI programme. Ketoconazole strongly inhibited the metabolism of maraviroc in vitro, and this is the likely explanation for the increase in maraviroc AUC seen when ketoconazole is co-administered with maraviroc. Use of the reversible $K_{l}$ for ketoconazole captured the magnitude of the interaction with maraviroc, and this model has also been shown to simulate the well-characterized interaction between midazolam and ketoconazole [23].

Similarly, ritonavir, atazanavir and saquinavir are all CYP3A4 inhibitors of varying potency - all three compounds are also reported to be mechanism-based inhibitors of CYP3A4 $[12,14,16]$, and ritonavir is also an inducer of CYP3A4 [24]. However, whereas atazanavir and saquinavir required use of $K_{l}$ and $k_{\text {inact }}$ (time-dependent inhibition parameters) in the model to capture the magnitude of the DDI with maraviroc, the ritonavir model used a reversible $K_{l}$ for CYP3A4. For both the saquinavirmidazolam [25] and ritonavir-midazolam (J. Unadkat, personal communication, June 2006) interactions, the magnitude of clinical DDIs with midazolam have been accurately simulated in Simcyp ${ }^{\mathrm{TM}}$ (data not shown) using the time-dependent inhibition (TDI) model for saquinavir and the reversible inhibition model for ritonavir. Whereas saquinavir and atazanavir are relatively weak reversible

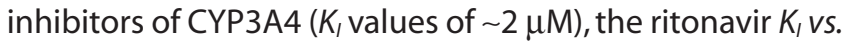
CYP3A4 is two orders of magnitude lower and hence the model can capture the magnitude of the DDI using the reversible $K_{l}$ alone [26]. In contrast, both saquinavir and atazanavir are predicted to elicit an AUC change of 1.5× increase in maraviroc AUC using the reversible $K_{l}$ input, much lower than the values seen in the clinic $(4.3 \times$ and $3.6 \times$ increases in maraviroc AUC, respectively) [10].

When TDI parameters vs. CYP3A4 for ritonavir $\left(K_{l}=0.17 \mu \mathrm{M}\right.$ and $k_{\text {inact }}=24 \mathrm{~h}^{-1}$ [14]) were incorporated in the model, the midazolam AUC increase was overpredicted by 3.5 -fold (data not shown). One possible reason for overprediction could be CYP3A4 induction, which is not accounted for in the model. However, this seems unlikely, as no induction of CYP3A4 by ritonavir (by monitoring 1'-OH midazolam/midazolam ratio) has been observed after long-term administration of the drug at $200 \mathrm{mg}$ bid [27]. Furthermore, induction did not appear to contribute to the saquinavir-ritonavir interaction, where the ritonavir reversible $K_{l}$ model [28] has been shown to simulate accurately the clinical interaction [29] between saquinavir (as substrate) and ritonavir (inhibitor).

Maraviroc kinetics are supraproportional to dose up to $300 \mathrm{mg}$ bid, which has been attributed to P-gp involvement in maraviroc disposition. The compound has been shown to be a moderate affinity substrate of P-gp, with a $K_{m}$ of $37 \mu \mathrm{M}$ [2], and hence the transporter may be saturated with increasing dose levels. The clinical data support this theory, with near complete absorption of maraviroc at a dose of $300 \mathrm{mg}$ [2], believed to be due to complete saturation of maraviroc efflux (thought to be mediated by $\mathrm{P}$-gp). There is in vitro evidence to demonstrate that all the CYP3A4 inhibitors investigated here can inhibit P-gp activ- 
ity [30-33]. Clinical DDIs with maraviroc could also be due in part to interactions with transporters. However, at clinically relevant doses of maraviroc P-gp is thought to be fully saturated. In addition, we have shown that the magnitude of the DDI is accurately simulated by the inhibition of CYP3A4-mediated clearance alone. It is therefore believed that interactions with CYP3A4 rather than P-gp are the major mechanism for the maraviroc AUC increase in the presence of these inhibitors.

We have demonstrated that maraviroc is predominantly metabolized by CYP3A4, and is not itself an inhibitor of CYP enzymes. The pharmacokinetics of maraviroc is predicted to be affected by modulators of CYP3A4, but maraviroc is not predicted to affect the metabolism of other compounds metabolized by CYP. We have built a model within Simcyp ${ }^{\mathrm{TM}}$ that simulates maraviroc pharmacokinetics and CYP-based interactions. The simulated maraviroc oral clearance values are in keeping with those observed in the clinic, as are the magnitude of DDls for saquinavir, ketoconazole and atazanavir. For ritonavir, in vivo data were accurately simulated only when a competitive inhibition model (rather than time-dependent inhibition model) was used. Similar observations have been made by others, suggesting further refinement of the ritonavir model is required. The availability of a reliable Simcyp ${ }^{\mathrm{TM}}$ model, validated against clinical data, allows for prediction of other DDIs without the need for clinical studies.

\section{REFERENCES}

1 Dorr P, Westby M, Dobbs S, Griffin P, Irvine B, Macartney M, Mori J, Rickett G, Smith-Burchnell C, Napier C, Webster R, Armour D, Price D, Stammen B, Wood A, Perros M. Maraviroc (UK-427,857), a potent, orally bioavailable, and selective small-molecule inhibitor of chemokine receptor ccr5 with broad-spectrum anti-human immunodeficiency virus type 1 activity. Antimicrob Agents Chemother 2005; 49: 4721-32.

2 Walker DK, Abel S, Comby P, Muirhead GJ, Nedderman AN, Smith DA. Species differences in the disposition of the CCR5 antagonist, UK-427,857, a new potential treatment for HIV. Drug Metab Dispos 2005; 33: 587-95.

3 Fatkenheuer G, Pozniak AL, Johnson MA, Plettenberg A, Staszewski S, Hoepelman Al, Saag MS, Goebel FD, Rockstroh JK, Dezube BJ, Jenkins TM, Medhurst C, Sullivan JF, Ridgway C, Abel S, James IT, Youle M, van der Ryst E. Efficacy of short-term monotherapy with maraviroc, a new CCR5 antagonist, in patients infected with HIV-1. Nat Med 2005; 11:1170-2.

4 Yeni PG, Hammer SM, Hirsch MS, Saag MS, Schechter M, Carpenter CC, Fischl MA, Gatell JM, Gazzard BG, Jacobsen DM, Katzenstein DA, Montaner JS, Richman DD, Schooley RT, Thompson MA, Vella S, Volberding PA. Treatment for adult HIV infection: 2004 recommendations of the International AIDS Society-USA Panel. JAMA 2004; 292: 251-65.
5 Tseng AL, Foisy MM. Management of drug interactions in patients with HIV. Ann Pharmacother 1997; 31: 1040-58.

6 Abel S, Russell D, Whitlock LA, Ridgeway CE, Nedderman ANR, Walker DK. Assessment of the absorption, metabolism, and absolute bioavailability of maraviroc in healthy male subjects. Br J Clin Pharmacol 2008; 65 (Suppl. 1): 60-7.

7 Hyland R, Roe EG, Jones BC, Smith DA. Identification of the cytochrome $\mathrm{P} 450$ enzymes involved in the $\mathrm{N}$-demethylation of sildenafil. Br J Clin Pharmacol 2001; 51: 239-48.

8 Walsky RL, Obach RS. Validated assays for human cytochrome P450 activities. Drug Metab Dispos 2004; 32: 647-60.

9 Walsky RL, Obach RS, Gaman EA, Gleeson JP, Proctor WR. Selective inhibition of human cytochrome P4502C8 by montelukast. Drug Metab Dispos 2005; 33: 413-8.

10 Abel S, Russell D, Taylor-Worth RJ, Ridgeway CE, Muirhead GJ. Effects of CYP3A4 inhibitors on the pharmacokinetics of maraviroc in healthy volunteers. Br J Clin Pharmacol 2008; 65 (Suppl. 1): 27-37.

11 Goldsmith DR, Perry CM. Atazanavir. Drugs 2003; 63: 1679-93; discussion 1694-5.

12 Bristol-Myers Squibb C. Reyataz NDA 021567; FDA Approved Drug Products. Available at http://www.accessdata.fda.gov/ scripts/cder/drugsatfda/index.cfm (last accessed: 22 April 2008).

13 Proctor NJ, Tucker GT, Rostami-Hodjegan A. Predicting drug clearance from recombinantly expressed CYPs: intersystem extrapolation factors. Xenobiotica 2004; 34: 151-78.

14 Ernest CS II, Hall SD, Jones DR. Mechanism-based inactivation of CYP3A by HIV protease inhibitors. J Pharmacol Exp Ther 2005; 312: 583-91.

15 Mayhew BS, Jones DR, Hall SD. An in vitro model for predicting in vivo inhibition of cytochrome P450 3A4 by metabolic intermediate complex formation. Drug Metab Dispos 2000; 28: 1031-7.

16 Obach RS, Walsky RL, Venkatakrishnan K. Mechanism-based inactivation of human cytochrome p450 enzymes and the prediction of drug-drug interactions. Drug Metab Dispos 2007; 35: 246-55.

17 Poulin P, Theil FP. A priori prediction of tissue: plasma partition coefficients of drugs to facilitate the use of physiologically-based pharmacokinetic models in drug discovery. J Pharm Sci 2000; 89: 16-35.

18 Austin RP, Barton P, Cockroft SL, Wenlock MC, Riley RJ. The influence of nonspecific microsomal binding on apparent intrinsic clearance, and its prediction from physicochemical properties. Drug Metab Dispos 2002; 30: 1497-503.

19 Rostami-Hodjegan A, Tucker GT. Simulation and prediction of in vivo drug metabolism in human populations from in vitro data. Nat Rev Drug Discov 2007; 6: 140-8.

20 Rendic S. Summary of information on human CYP enzymes: human P450 metabolism data. Drug Metab Rev 2002; 34: 83-448. 
21 Pfizer Inc. Selzentry NDA 022128; FDA Approved Drug Products. Available at http://www.accessdata.fda.gov/ scripts/cder/drugsatfda/index.cfm (last accessed: 22 April 2008).

22 Abel S, Russell D, Whitlock LA, Ridgeway CE, Muirhead GJ. Effects of maraviroc on the pharmacokinetics of midazolam, lamivudine/zidovudine, and oral contraceptives in healthy volunteers. Br J Clin Pharmacol 2008; 65 (Suppl. 1): 19-26.

23 Rowland-Yeo K, Jamei M, Yang J, Tucker GT, Rostami-Hodjegan A. Prediction of in vivo drug interactions from in vitro enzyme kinetic data: time based versus steady state simulations. 2007. Available at http://www.simcyp.com/ ResearchDevelopment/Publications/Posters/default.htm (last accessed: 22 April 2008).

24 Hsu A, Granneman GR, Witt G, Locke C, Denissen J, Molla A, Valdes J, Smith J, Erdman K, Lyons N, Niu P, Decourt JP, Fourtillan JB, Girault J, Leonard JM. Multiple-dose pharmacokinetics of ritonavir in human immunodeficiency virus-infected subjects. Antimicrob Agents Chemother 1997; 41: 898-905.

25 Palkama VJ, Ahonen J, Neuvonen PJ, Olkkola KT. Effect of saquinavir on the pharmacokinetics and pharmacodynamics of oral and intravenous midazolam. Clin Pharmacol Ther 1999; 66: 33-9.

26 Einolf HJ. Comparison of different approaches to predict metabolic drug-drug interactions. Xenobiotica 2007; 37: 1257-94.

27 Fellay J, Marzolini C, Decosterd L, Golay KP, Baumann P, Buclin T, Telenti A, Eap CB. Variations of CYP3A activity induced by antiretroviral treatment in HIV-1 infected patients. Eur J Clin Pharmacol 2005; 60: 865-73.
28 Almond L, Rowland Yeo K, Howgate E, Tucker GT, Rostami-Hodjegan A. Mechanistic prediction of HIV drug-drug interactions in virtual populations from in vitro enzyme kinetic data: ritonavir and saquinavir. 2007. Available at http://www.simcyp.com/ResearchDevelopment/ Publications/Posters/default.htm (last accessed: 22 April 2008).

29 Buss N, Snell P, Bock J, Hsu A, Jorga K. Saquinavir and ritonavir pharmacokinetics following combined ritonavir and saquinavir (soft gelatin capsules) administration. $\mathrm{Br} \mathrm{J}$ Clin Pharmacol 2001; 52: 255-64.

30 Chinn LW, Gow JM, Tse MM, Becker SL, Kroetz DL. Interindividual variability in the effect of atazanavir and saquinavir on the expression of lymphocyte P-glycoprotein. J Antimicrob Chemother 2007; 60: 61-7.

31 Huisman MT, Smit JW, Wiltshire HR, Hoetelmans RM, Beijnen JH, Schinkel AH. P-glycoprotein limits oral availability, brain, and fetal penetration of saquinavir even with high doses of ritonavir. Mol Pharmacol 2001; 59: 806-13.

32 Rautio J, Humphreys JE, Webster LO, Balakrishnan A, Keogh JP, Kunta JR, Serabjit-Singh CJ, Polli JW. In vitro p-glycoprotein inhibition assays for assessment of clinical drug interaction potential of new drug candidates: a recommendation for probe substrates. Drug Metab Dispos 2006; 34: 786-92.

33 Smalley J, Marino AM, Xin B, Olah T, Balimane PV. Development of a quantitative LC-MS/MS analytical method coupled with turbulent flow chromatography for digoxin for the in vitro P-gp inhibition assay. J Chromatogr B Analyt Technol Biomed Life Sci 2007; 854:260-7. 